\title{
Study of Experimental Investigations in the Presence of Ceramic Waste Powder
}

\author{
MOHAMED FARSANE ${ }^{1 *}$, ABDELLAH ANOUAR ${ }^{2}$, SOUAD CHAH $^{1}$, SAID DAGDAG $^{3}$, \\ MILOUD BOUZZIRI ${ }^{1}$
}

${ }^{1}$ Hassan First University of Settat, Faculty of Science and Technology, Laboratory of Physico-Chemistry of Processes and Materials (PCPM), Morocco

${ }^{2}$ Hassan First University of Settat, Faculty of Science and Technology, Laboratory of Applied Chemistry and Environment, Morocco

${ }^{3}$ Hassan First University of Settat, Faculty of Science and Technology, Laboratory of Environmental and Developmental Sciences, Morocco

\begin{abstract}
The paper aims to evaluate the gel time and exotherm temperature properties of the curing of unsaturated polyester resin at various amounts of Methyl ethyl ketone peroxide, cobalt octoate and porcelain powder. The gel time of samples are determined using the simple method, while the exotherm temperature are evaluated using the thermocouple. The variation of these properties is discussed theoretically and experimentally.
\end{abstract}

Keywords: nsaturated polyester resin, porcelain powder, gel time, exotherm temperature, curing process

\section{Introduction}

Today, unsaturated polyester resins (UPRs) plays an important role in the industry mainly due to its low price, easier handling, as well as ease of association with reinforcement $[1,2]$.

The curing of this polyester backbone by the unsaturated acid constituent in combination with a vinyl component creates a three-dimensional structure [3].

Considering that in industrial formulations, several additives are included in a curing process, resulting in complicated cure kinetics. So, The cure kinetics UPR are commonly very complex because numerous reactive processes are taking place at the same time [4]. In addition, a number of crucial events, such as kinetics of reactions, phase separation, changes in rheology and microstructure formation, control the workability of the polymers as well as the characteristics of the final end product, which are major variables in the cure process of these thermosets [5]. Therefore, it is difficult to find direct and accurate results in predicting the properties of polymers based on their composition [6].

In the pre-reaction, the resin is a viscous liquid. It then becomes more and more viscous over the course of the reaction. The rise in the viscosity is due to the formation of macromolecules. Due to crosslinking at the multi-unsaturation points of the polyester molecules, the reaction system will finally form a macro network and then result in an indefinite viscosity. This is known as "gelling". Hsu et al have classified the process of curing on five steps [7].

The point of gelation can be identified more easily by occasional stirring, although other more sophisticated methods are available. the gelation time corresponds closely to the initial rise in temperature [8], therefore, the induction period of reaction correspond closely to the gel point. In addition, gel times for free radical cross-linkage are known to occur at low conversion [9]. Up to the gel point, most of the reaction will take place between the inhibitor and the radicals, Hsu et al [7], found that the formation of the microgels at which the reaction begins is an important characteristic in free-radical multifunctional chain-growth polymerization.

Considering that a tridimensional structure will develop soon after the initiation of free radical curing, it is important to be able to understand how the induction process will depend on the initiator systems, the control of gelation as well as curing rate for polyester resins to their use in various applications. 
A review of the data in the literature shows that there are some references, so that the increase in methyl ethyl ketone peroxide and promoter cobalt naphthenate causes a decrease in freezing time [8], [10]. Yang et al. [11] correlated the curing conditions such as curing temperature, initiator concentration, and acceleration concentration with the gelation.

The combination of a filler with a resin leads to a new product with new properties. Some of all of these changes are advantageous but others are less favourable [6]. Kubota [12] reported that the presence of a high quantity of filler in the cure system increased both the thermal conductivity and the viscosity of the resin; however, it reduced the concentration of reactive double bonds per unit volume. The first two factors enhanced the cure reactions, the last factor had an unfavourable effect on cure. According to his observations, with increasing filler content the cure started at a lower temperature; however, the total heat of cure decreased with increasing filler content. Lucas and co-workers [13] reported a decrease in the induction period of the styrene/ polyester system cured in the presence of $\mathrm{CaCO}_{3}$, as a filler. This effect was attributed to preferential adsorption of inhibitors, including dissolved oxygen, in the fillerrich phase. McGee [14] applied a simple nth order model to demonstrate the effect of particulate fillers on the heat transfer and cure process. He reported that the gel time of polyester system increased with increasing the glass content.

Theoretical and experimental analyses [8, 10, 11, 15-22] have focused on the curing of thermoset resin. In generally, curing of thermoset resins has been mostly investigated by Fourier transform infrared spectroscopy [23-25], pseudo-adiabatic exotherm [8, 26], gel time measurements [27,28]. Differential scanning calorimetry (DSC) is among the most common methods in the determination of kinetic parameters $[15,25,28-30]$.

The different expressions to predict the cure reactions and kinetics used for this study were reviewed by Rammis [15], and Cook et al [8] for different unsaturated polyester resin systems.

In this research, the kinetics of curing of UPR are investigated by the measurement of the gel time and pseudo-adiabatic exotherm behavior for resin initiated by varying levels of MEKP, a cobalt promoter. Effects of ceramic particles on the cure reactions are discussed in the second part.

\section{Theoretical predictions}

Taking the steady-state hypothetical for a radical at an increased concentration of cobalt and MEKP, the rate of polymerization $\left(\mathrm{R}_{\mathrm{p}}\right)$ of a monomer $(\mathrm{M})$ is defined by [31]:

$$
-\frac{d[M]}{d t}=k_{p}[M]\left[M_{n}\right]=k_{p}[M]\left(\frac{f R_{i}}{k_{t}}\right)^{1 / 2}
$$

In which $[\mathrm{M}]$ and $\left[\mathrm{M}_{\mathrm{n}}{ }_{\mathrm{n}}\right]$ are the monomer and radical concentrations, $\mathrm{f}$ is an initiation efficiency, $\mathrm{R}_{\mathrm{i}}$ is an initiator decomposition rate, $\mathrm{k}_{\mathrm{p}}$ and $\mathrm{k}_{\mathrm{t}}$ are the propagation and termination rate constants, respectively.

In all cases, the MEKP initiator decomposition using a metal promoter can be described by the expressions:

$$
\begin{array}{llll}
\mathrm{ROOH}+\mathrm{Co}^{2+} \longrightarrow & \mathrm{RO}+\mathrm{OH}^{-}+\mathrm{Co}^{3+}\left(\mathrm{K}_{\mathrm{d} 1}\right) & 1 \\
\mathrm{ROOH}+\mathrm{Co}^{3+} \longrightarrow & \mathrm{ROO}+\mathrm{H}^{+}+\mathrm{Co}^{2+}\left(\mathrm{K}_{\mathrm{d} 2}\right) & 2
\end{array}
$$

where $\mathrm{ROOH}$ and Co denote the MEKP and cobalt species, $\mathrm{k}_{\mathrm{d} 1}, \mathrm{k}_{\mathrm{d} 2}$ depict rate constants for the formation of alkoxy (RO) and peroxy (ROO) radicals, respectively. The decomposition of ROOH is the rate controlling step in free radical polymerization. Beaunez et al [32] noticed that the peroxy radical is considerably less reactive to ethylenic monomers compared to the alkoxy radical and therefore equation 1 gives the initiation rate. However, equation 2 is important as this step regenerates the $\mathrm{Co}^{2+}$, yielding a pseudo-stable state for its concentration of $\mathrm{Co}^{2+}$. As a consequence, the rate of formation of alkoxy radicals is predicted to be roughly constant up to the MEKP concentration is depleted as indicated by the reaction kinetics: 


$$
-\frac{d[R O O H]}{d t}=\frac{d[R O \cdot]}{d t}=K_{d 1}\left[\mathrm{Co}^{2+}\right][R O O H]
$$

If we suppose that a steady state is present for $\mathrm{Co}^{2+}$ formation, the initiation rate can be derived from [16]:

$$
R_{i}=\frac{K_{d 1} K_{d 2}[\mathrm{ROOH}]\left[\mathrm{Co}^{2+}\right]_{0}}{\left(K_{d 1}+K_{d 2}\right)}=K_{d}[R O O H]\left[\mathrm{Co}^{2+}\right]_{0}
$$

The combined Eq. (3) with Eq. (1) indicates that the rate of polymerization can be expected to increase with increasing cobalt and MEKP levels and this will be equal to:

$$
-\frac{d[M]}{d t}=K_{p}[M]\left(\frac{f K_{d 1} K_{d 2}[R O O H]\left[\mathrm{Co}^{2+}\right]_{0}}{K_{t}\left(K_{d 1}+K_{d 2}\right)}\right)^{1 / 2}=K_{p}[M]\left(f K_{d}[R O O H]\left[\mathrm{Co}^{2+}\right]_{0}\right)^{1 / 2}
$$

The expression of conversion can be written as:

then

$$
\alpha=\left(1-\frac{[M]}{[M]_{0}}\right)
$$

$$
\frac{d \alpha}{d t}=k_{p}(1-\alpha)\left(\frac{f k_{d}}{k t}\right)^{1 / 2}\left([R O O H]\left[C o^{2+}\right]_{0}\right)^{1 / 2}
$$

By integrating equation (2) and substituting $[\mathrm{ROOH}]$ in equation (6), we obtain the following equation:

$$
\frac{d \alpha}{d t}=k_{p}(1-\alpha)\left(\frac{f k_{d}}{k t}\right)^{1 / 2}\left([R O O H]_{0} e^{-k_{d 1}\left[\mathrm{Co}^{2+}\right]_{0} t}\left[\mathrm{Co}^{2+}\right]_{0}\right)^{1 / 2}
$$

We accept this approximation based on power series, and then the exponential can be written as:

$$
e^{-k_{d 1}\left[\mathrm{Co}^{2+}\right]_{0} t}=1-k_{d 1}\left[\mathrm{Co}^{2+}\right]_{0} t
$$

Replacing equation (8) in equation (7) gives:

$$
\frac{d \alpha}{d t}=k_{p}(1-\alpha)\left(\frac{\left[\mathrm{Co}^{2+}\right]_{0}}{k t}\right)^{1 / 2}\left(f k_{d}[R O O H]_{0}\left(1-k_{d 1}\left[\mathrm{Co}^{2+}\right]_{0} t\right)\right)^{1 / 2}
$$

We describe A, B, C as:

$$
\mathrm{A}=k_{p}\left(\left(\frac{\left[\mathrm{Co}^{2+}\right]_{0}}{k t}\right)^{1 / 2}, \mathrm{~B}=f k_{d}[R O O H]_{0}, \mathrm{C}=f k_{d} k_{d 1}[R O O H]_{0}\left[\mathrm{Co}^{2+}\right]_{0}\right.
$$

Substituting A, B and C in Eq. (9) and simple integration between 0 and t we obtain:

$$
\int_{0}^{\alpha} \frac{d \alpha}{1-\alpha}=\int_{0}^{t} A(B-C t)^{1 / 2} d t
$$

Then

$$
-\ln (1-\alpha)=-\frac{2 A}{3 C}\left((B-C t)^{3 / 2}-B^{3 / 2}\right)
$$

$\mathrm{C}$ is much larger than $\mathrm{B}$, so $(\mathrm{B}-\mathrm{Ct})^{3 / 2}$ in Eq. (10) can be developed as a power series:

$$
-\ln (1-\alpha)=-\frac{2 A}{3 C}\left(\left(B^{3 / 2}-\frac{3}{2} C B^{1 / 2} t\right)-B^{3 / 2}\right)\left(f k_{d}[R O O H]_{0}\right)^{1 / 2}
$$


The simplification of Eq. (12) gives:

Replacing A and B in Eq (13), gives:

$$
t=-\frac{\ln (1-\alpha)}{A B^{1 / 2}}
$$

$$
t=-\frac{\ln (1-\alpha)}{k_{p}\left(\left(\frac{\left[\mathrm{Co}^{2+}\right]_{0}}{k t}\right)^{1 / 2}\left(f k_{d}[R O O H]_{0}\right)^{1 / 2}\right.}
$$

And finally by introducing the logarithm in Eq. (14) gives the following expression:

$$
\ln (t)=\ln \left(-\frac{\ln (1-\alpha)}{k_{p}\left(f f k_{d} \frac{\left[C o^{2+}\right]_{0}}{k_{t}}\right)^{\frac{1}{2}}}\right)-1 / 2\left([R O O H]_{0}\right)
$$

For a specified temperature with a constant conversion degree, the relationship between $\ln (\mathrm{t})$ and $\ln \left([\mathrm{ROOH}]_{0}\right)$ is linear.

The induction step is affected by the inhibitor which consumes the radicals produced by the initiators. Due to the constant high reaction rate constant between radical and inhibitor, the propagation of radicals is eliminated by the inhibition reaction.

If the Inhibition reactions are faster than propagation reactions. Thus, the concentration of inhibitor is greater than the radical concentration; consequently, no significant polymerization will occur. As the inhibitor is depleted, the monomer will react with the radical and polymerization will occur.

The following expression describes the mechanism of inhibition is:

$$
\mathrm{R}^{*}+\mathrm{Z} \longrightarrow \mathrm{RZ} \quad\left(\mathrm{K}_{\mathrm{z}}\right)
$$

The corresponding kinetic equation for the inhibition is given by:

$$
\frac{d Z}{d t}=-k_{z}[Z][R \cdot]
$$

In addition, the rate of change in radical concentration is described in literature [8] by the following expression:

$$
\frac{d[R \cdot]}{d t}=k_{d}[R O O H]\left[\mathrm{Co}^{2+}\right]-k_{Z}[Z]\left[R^{\cdot}\right]
$$

If no propagation takes place, the radicals will be consumed at the same rate at which they are produced (quasi-steady-state approximation : $\frac{d[R \cdot]}{d t}=0$ )

Then

$$
[R \cdot]=\frac{k_{d}[\mathrm{ROOH}]\left[\mathrm{Co}^{2+}\right]}{k_{z}[Z]}
$$

Hence, rate of inhibitor loss is indicated by:

$$
\frac{d Z}{d t}=-k_{d}[R O O H]\left[\mathrm{Co}^{2+}\right]
$$

When there is no more inhibitor, the polymerization reaction can commence. Therefore, the rate of loss of inhibitor is the rate controlling step in free radical polymerization and practically induction time of the curing reaction.

By integrating of Eq. (19), we obtain the following expression:

$$
[Z]_{0}=[Z]-k_{d}[R O O H]\left[\mathrm{Co}^{2+}\right] \mathrm{t}
$$


Now define the inhibition time $t_{z}$ as the time at which the concentration of radicals would be zero until the present conditions as noted by the author in publication [8].

Therefore, from Eq. (20), the overall expression describing the induction time can be given as:

$$
\mathrm{t}_{\mathrm{z}}=\frac{[\mathrm{Z}]_{0}}{\mathrm{k}_{\mathrm{d}}[\mathrm{ROOH}]\left[\mathrm{Co}^{2+}\right]}
$$

This formula is analogous to the one found in other workers [33]. For periods longer than $t_{z}$, the free radicals react with the monomers and produce heat.

\section{Materials and methods}

A commercial general-purpose orthophtalic polyester resin was employed. The specific gravity of the resin was 1.3 , Viscosity at $25^{\circ} \mathrm{C}$ was $7.5-9$ poises, Acid Value was $20-30 \mathrm{mgKOHg}$, and the styrene content was $34 \%$. Ceramic sanitary wares, such as basins, toilets, bathrooms, and sinks, were collected from public landfills in Settat, Morocco. These devices were broken with a hammer and crushed in a crusher to obtain a granular material with particles smaller than $4 \mathrm{~mm}$ in diameter. The ceramic waste was then dry milled in alumina media (30\% alumina balls, 30\% ceramic waste, and $40 \%$ air) for $30 \mathrm{~min}$ to obtain a ceramic powder. Ceramic powders with a particle size $<180 \mu \mathrm{m}$ were chosen for this investigation.

Methyl ethyl ketone peroxide (MEKP) and cobalt octoate (Co) were employed as initiator and accelerator. The MEKP varied from $1-2 \%$ by mass of UPR, whereas the Co varied between $0.12-1 \%$ by mass of UPR. The resin or resin filler was prepared by adding the required amount of initiator at ambient; next, the required dose of accelerator was applied and the mixture was mixed shortly afterwards. The gel time was established by manual stirring from time-to-time. At all times, the curing exotherm was obtained by positioning a thermocouple in the centre of an adequate quantity of catalysed resin or resin filler in a glass specimen and initially kept at room temperature. Table 1 shows the different experiments carried out during this study.

Table 1. Effect of recycled ceramic waste (PP) content, MEKP and Co on curing characteristics (gel time $\left(\mathrm{t}_{\mathrm{gel}}\right)$, time to peak $\left(\mathrm{t}_{\max }\right)$ ) and Peak Temp $\left(\mathrm{T}_{\max }\right)$

\begin{tabular}{|c|c|c|c|}
\hline \multirow{2}{*}{$\begin{array}{c}\text { MEKP + Co + PP } \\
(\%)\end{array}$} & \multicolumn{3}{|c|}{ Parameter } \\
\cline { 2 - 4 } & $\mathbf{t}_{\text {gel }}(\min )$ & $t_{\max }(\min )$ & $\mathbf{T}_{\max }\left({ }^{\circ} \mathbf{C}\right)$ \\
\hline $2+0.5+--$ & 06.30 & 11.00 & 190 \\
$1.5+0.5+--$ & 09.15 & 13.30 & 170 \\
$1+0.5+--$ & 13.00 & 19.30 & 165 \\
\hline $2+0.12+--$ & 09.15 & 13.45 & 180 \\
$2+0.5+-$ & 06.30 & 11.00 & 190 \\
$2+1+--$ & 04.45 & 09.15 & 189 \\
\hline $2+0.5+0$ & 06.30 & 11.00 & 190 \\
$2+0.5+28.5$ & 09.45 & 15.45 & 146 \\
$2+0.5+41$ & 10.15 & 16.30 & 136 \\
$2+0.5+50$ & 13.00 & 18.30 & 123 \\
\hline
\end{tabular}

The exotherm rise $\left(\mathrm{T}_{\exp }\right)$ was corrected for heat loss to the environment by using the heat balance of Rojas et al methodology [26]. The conversion values at each time are derived from the equations below:

$$
\begin{gathered}
T_{a d}=T_{e x p}+\int_{0}^{t} U^{\prime}\left(T_{e x p}-T_{0}\right) d t \\
\alpha=\frac{T_{a d}-T_{0}}{T_{a d, \text { max }}-T_{0}}
\end{gathered}
$$


Where $T_{a d}$ is the corrected temperature for adiabatic conditions, $T_{o}$ is the ambient temperature, $\alpha$ is the degree of conversion, and $U^{\prime}$ is the ratio of the global heat transfer coefficient per unit mass to the specific heat, and assumed to be constant. A plot of $\ln \left(\mathrm{T}_{\exp }-\mathrm{T}_{\mathrm{o}}\right)$ vs time gives a straight line from a certain time after the experimental maximum temperature. The U' value is obtained by calculating the gradient of this line.

\section{Results and discussions}

Figure 1 shows the thermograms of an unsaturated polyester resin cured isothermally at ambient using different amounts of benzoyl peroxide as an initiator. The effect of the initiator on the curing process is evident. Thus, the induction period decreases with increasing the level of MEKP. This is consistent with the prediction of eq. (4), which shows that the rate should increase as the peroxide concentration is raised. This is due to increases of decomposition of MEKP molecules and rapidly produces alkoxy and peroxy radicals which initiate the polymerization reactions as described in the kinetic scheme. The results of the gel time in Figure 3 support the accelerating reaction due to the increases in peroxide concentrations (Table 1). This is primarily because of an increase in free radical generated due to the decomposition of catalyst by the accelerator.

These free radicals initiate the exothermic copolymerisation reaction. In the course of radical polymerisation, the heat evolved results in temperature rise. Consequently, the heat accumulation increases the rate and polymer molecular weight. As suggested by equation (21), gel time is inversely dependent on initiator level over the majority of the initiator range investigated, this is consistent with the gel time results of other workers [8, 17].

On the other hand $\Delta \mathrm{T}_{\mathrm{ad}}$, max did not remain constant for MEKP values ranging from 1.0 to 2.0 percent, so the initiator may be depleted before the completion of the reaction, and the reaction had not gone to completion. In the measured exotherm data, the temperature then decreases due to heat loss to the environment: this stage is virtually eliminated in the heat loss corrected exotherm curves which allow for this effect [8].

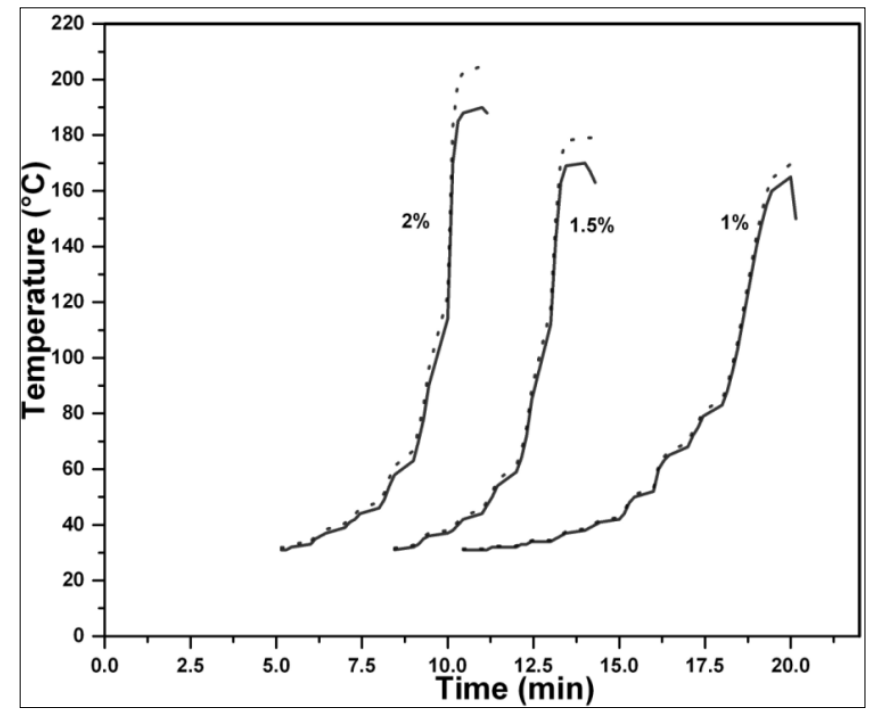

Figure 1. Temperature vs. time using with varying level of MEKP $(0.5 \mathrm{wt} \% \mathrm{Co})$. ( $ـ$ : Experimental data; ...... data calculated from equation (22)) 


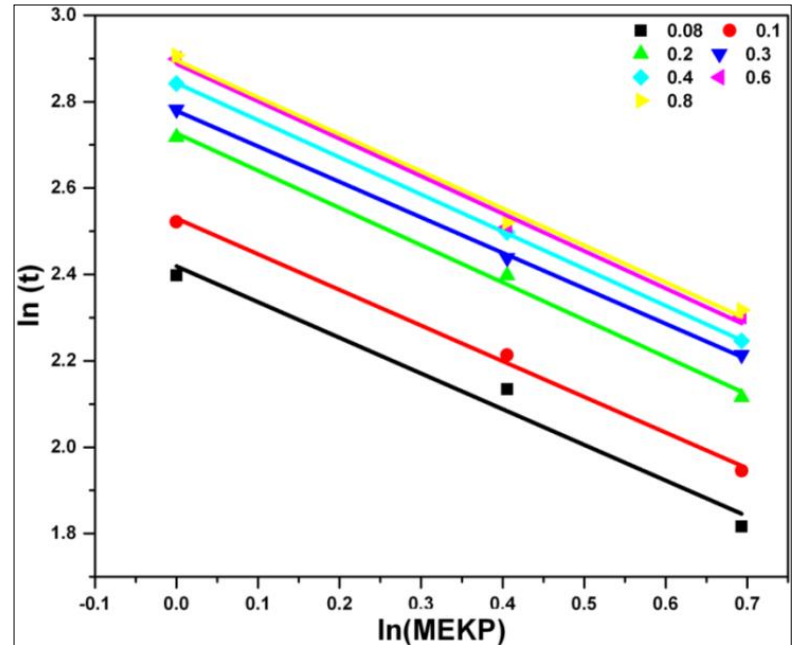

Figure 2. Plots of $\ln (\mathrm{t})$

vs. $\ln (\mathrm{MEKP})_{0}$ at different conversion degree

In Figure 2, the $\ln (t)$ is plotted against the logarithm of initial concentration at different conversion. The regression coefficient is more than 0.9. This finding shows that the relationship in equation (15) is valid for describing the cure of UPR. From the slope of the fitted curve, one obtains the kinetic parameters, $b$, which indicates that $b$ varies between 0.8 and 0.85 (Table 2). The values are very similar, suggesting that no change in reaction mechanism. Similar found was described in literature. Vafayan et al [17]. reported that the kinetic parameter, b, for MEKP was raised of 0.8401 to 1.0047 as the degree of conversion risen from 0.08 to 0.8 .

Table 2. Values of $\mathbf{b}$ at different conversion degree

\begin{tabular}{|l|l|l|l|}
\hline Conversion & Equation & Correlation coefficient & b \\
\hline 0.08 & $Y=-0.826 x+2.418$ & 0.997 & 0.826 \\
0.10 & $Y=-0.826 x+2.529$ & 0.996 & 0.826 \\
0.20 & $Y=-0.863 x+2.763$ & 0.996 & 0.863 \\
0.30 & $Y=-0.821 x+2.778$ & 0.999 & 0.821 \\
0.40 & $Y=-0.859 x+2.843$ & 0.999 & 0.859 \\
0.60 & $Y=-0.866 x+2.887$ & 0.994 & 0.866 \\
0.80 & $Y=-0.856 x+2.859$ & 0.994 & 0.856 \\
\hline
\end{tabular}

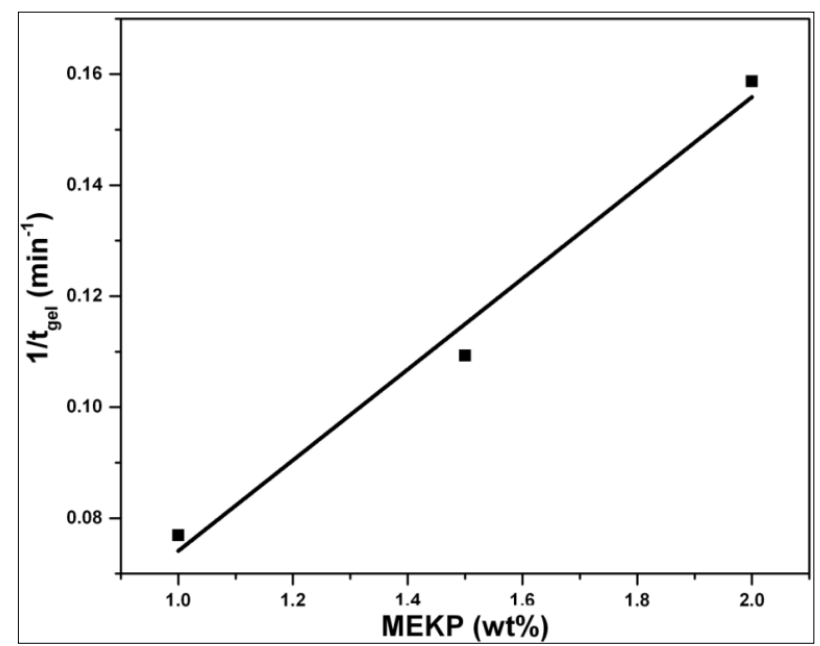

Figure 3. Gel time vs. concentration of MEKP at a constant 0.5 wt $\%$ Co

In Figure 4, the evolution of the temperature versus time is presented for the curing of UPR. For these data, the curing system was $2 \%$ by weight of MEKP, but with different levels of accelerator varying from 0.12 to $1 \%$ (Table 1). The decrease in cobalt concentrations prolongs the induction period as well as slowing this reaction. Gel time data in relation to cobalt levels are presented in Figure 5. At low 
concentrations of cobalt the gel time is reciprocally related to the promotor concentration as predicted by Eq. (21). These results are in good agreement with the literature [8, 11, 17].

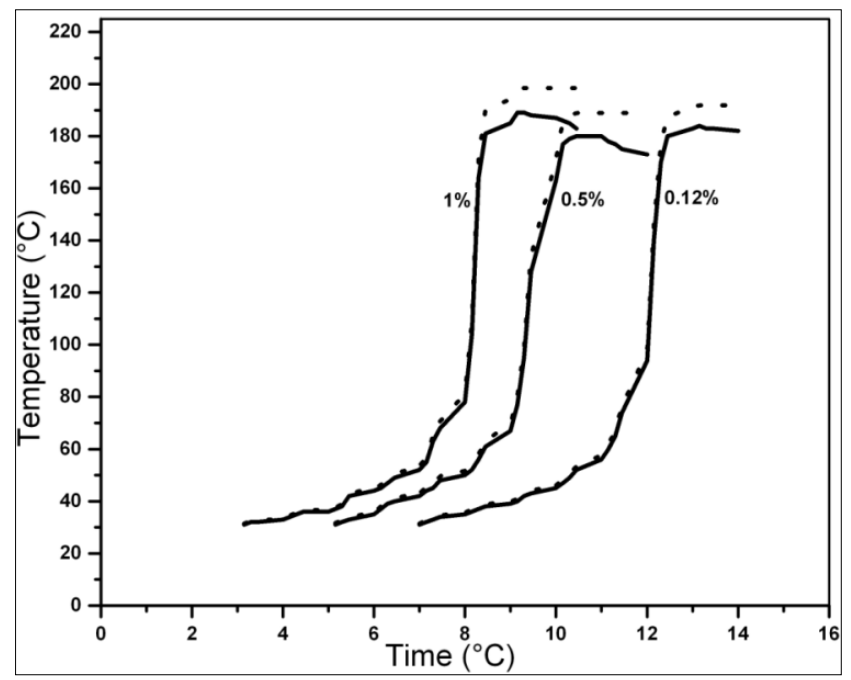

Figure 4. Temperature vs. time using with varying level of Co (2wt\% MEKP). ( — : Experimental data; .....: data calculated from equation (22))

It is notable that, in contrast to the results obtained for variable peroxides, the corrected exotherm is independent of the cobalt salt concentration, which suggests that the "full reaction" proceeds at low initiation rates, as the $\mathrm{Co}^{2+}$ species is not consumed in the reaction but is recuperated as described in equation (4).

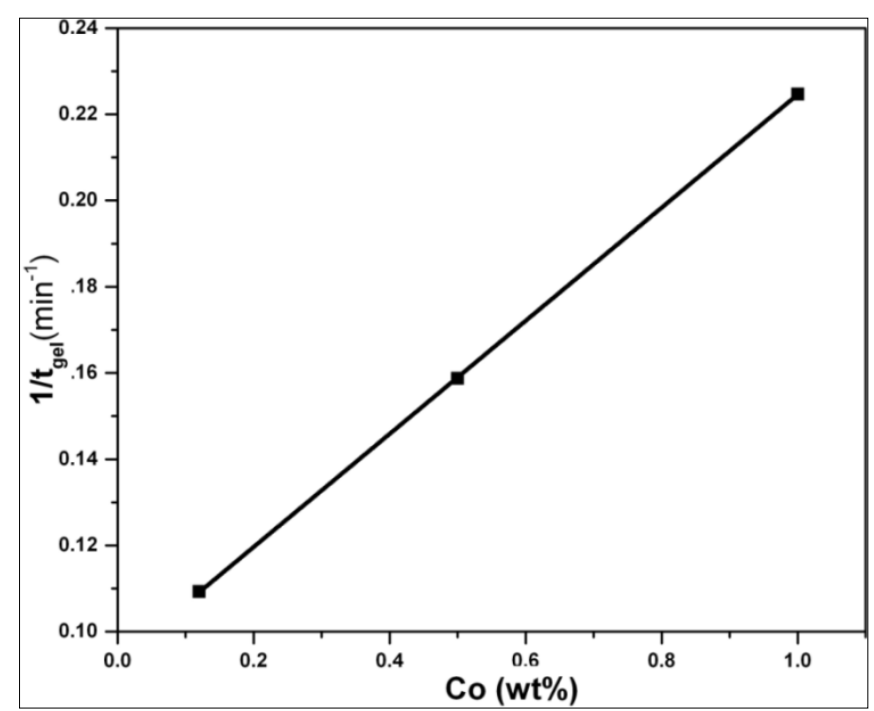

Figure 5. Gel time vs. concentration of cobalt octoat at a constant 2 wt \% MEKP

This paper will focus on unsaturated polyester resin in conjunction with porcelain powder obtained from waste ceramics. There were four different combinations tested.

They were: each resin with UPR) no PP, A1) $28.5 \%$ PP, A2) $41.0 \%$ PP, A3) $50 \%$ PP.

Figure 6 indicates that the introduction of $\mathrm{PP}$ in the resin caused a delay in the curing process of UPR. For the system (2.0\% MEKP, $0.5 \% \mathrm{Co})$, the influence of PP on the retardation of the cure reaction succeeded in the order: A3 > A2> A1 > UPR. 


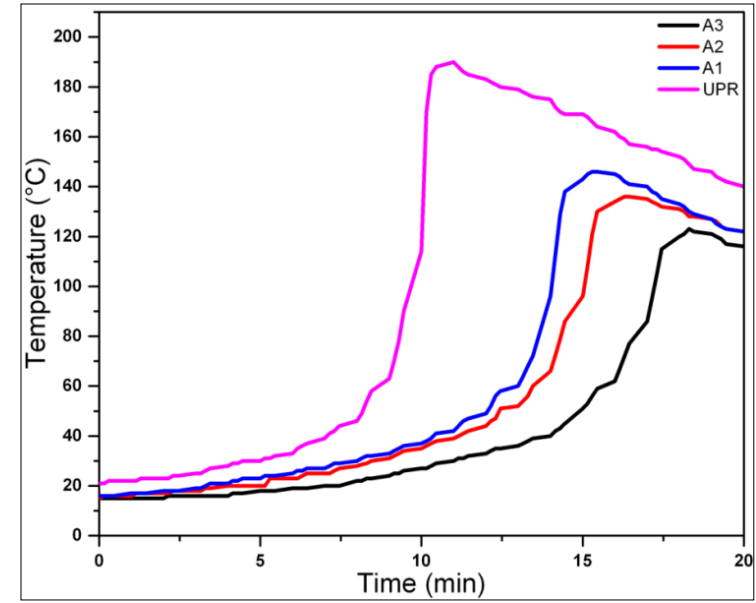

Figure 6. Temperature vs. time (2 wt \%: MEKP, $0.5 \mathrm{wt} \%$ Co) with varying amount of $\mathrm{PP}$

Figure 7 depicts an increase in $t_{\text {gel }}$ when the quantity of PP increases. The rise in gel time can be attributed to the retardation of the cross-linkage of the UPR and the absorption of the heat generated in the exotherm reaction. Rheological measurements carried out by simitziz [10] showed that the inorganic fillers (talc, and quartz) lead to an increase in the gel time delaying the crosslinking of the UPR. They reported that the microgels formed cannot come close because they are impeded by the presence of the $\mathrm{PP}$, with the consequence that the transition stage and then the macrogelation are retarded.

Figure 1 indicates the maximum value of $\mathrm{T}_{\max }$ as $190^{\circ} \mathrm{C}$ at the highest level of MEKP. Its lowest value was observed as 165 at the lowest levels of both catalyst. This also can be attributed to the formation of increases free radicals at hight levels of catalyst. It can be noted that, the increase in accelerator level does not contribute significantly towards $T_{\max }$ at higher levels of catalyst (Figure 4 and Table 1).

The temperature of the reaction increases when rate of heat generation, due to copolymerization is larger than that of heat dissipation. As the decomposition of free radicals contributes towards an increases of heat accumulation, the presence of PP absorbs the heat in reaction. Thus, the maximum peak temperature was recorded as $146^{\circ} \mathrm{C}$ at the lowest settings of PP. The minimum value of the same could be seen as $123^{\circ} \mathrm{C}$ at the highest level of PP (Figure 6 and Table 1).

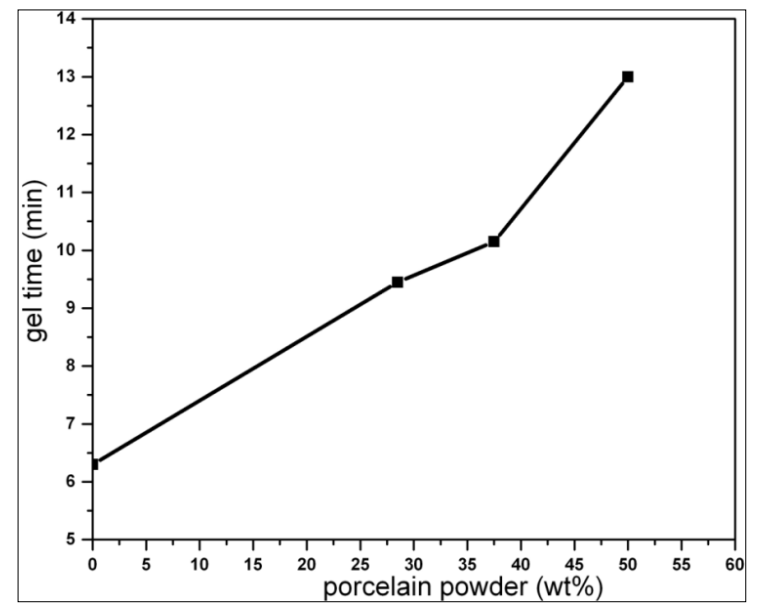

Figure 7. Gel time vs. concentration of PP (2 wt \% MEKP, $0.5 \mathrm{wt} \%$ Co)

The increase in filler content leads to a reduction in the total volume of resin, thus diminishing the amount of heat released per unit volume of the mixture in reaction. The degree of temperature decrease seems to be related to the filler content (Figure 6). 
The authors examined the action of fillers on the curing kinetics of an epoxy/anhydride resin. They concluded that the total heat of reaction reduces with the addition of fillers; hence, the fillers adsorb the monomers reacting on their surface, affecting the stoichiometry and create a steric barrier to the forming network [34].

However, to investigate this in depth, further research, such as FTIR and DSC studies, are necessary to understand these effects.

\section{Conclusions}

The influences of MEKP, Co, and porcelain powder on gel time and exotherm temperature were studied at room temperature. The gel time was found corresponding to the initial rise of temperature during resin curing and also the induction time was found to decreases as the concentrations of MEKP and Co increases.

The main effect of the filler is to change the temperature curves of the unsaturated polyester resin. So, for curing an unsaturated polyester resin, an increased content of porcelain powder will: decrease the maximum exothermic temperature, slow the reaction speed, and increase the gel time.

We proved that at ambient temperature and for a constant concentration of promoter, the logarithm of this reaction time ( $\mathrm{t}$ ) for all conversions can be described as a linear function of the logarithm of initiator concentration.

Acknowledgment: The author would like to thank Professors M. M BOUZZIRI, and M A. ANOUAR gave many helpful comments and suggestions during the course of this work.

\section{References}

1.B. CHERIAN E. T. Thachil, "Synthesis of unsaturated polyester resin - Effect of choice of reactants and their relative proportions," Int. J. Polym. Mater. Polym. Biomater., vol. 53, no. 10, pp. 829-845, 2004.

2.C. NEGOITA, N. CRISTACHE, M. BODOR, "The epoxy resin - History and perspectives," Mater. Plast., 53(3), 2016, 564-571

3.S. Y. TAWFIK, J. N. ASAAD, M. W. SABAA, "Effect of polyester backbone structure on the cured products properties," Polym. Test., vol. 22, no. 7, pp. 747-759, 2003.

4.K. DE LA CABA, P. GUERRERO, A. ECEIZA, I. MONDRAGON, "Kinetic and rheological studies of two unsaturated polyester resins cured at different temperatures," Eur. Polym. J., vol. 33, no. 1, pp. 19-23, 1997.

5.C. P. HSU L. J. LEE, "Free-radical crosslinking copolymerization of styrene/unsaturated polyester resins: 3. Kinetics-gelation mechanism," Polymer (Guildf)., vol. 34, no. 21, pp. 4516-4523, 1993.

6.I. G. BIRSAN, I. ROMAN, S. CIORTAN, "Tribological behavior prediction for an epoxy aramid system based on mechanical and thermal properties analyses," Dedic. to 50th Anniv. Year Tribol. - Proc. 8th Int. Sci. Conf. BALTTRIB 2015, pp. 134-141, 2016.

7.C. P. HSU L. J. LEE, "Free-radical crosslinking copolymerization of styrene/unsaturated polyester resins: 1. Phase separation and microgel formation," Polymer (Guildf)., vol. 34, no. 21, pp. 4496-4505, 1993.

8.W. D. COOK, M. LAU, M. MEHRABI, K. DEAN, MARCUS ZIPPER, "Control of gel time and exotherm behaviour during cure of unsaturated polyester resins," Polym. Int., vol. 50, no. 1, pp. 129134, 2001.

9.C. WALling, "Gel Formation in Addition Polymerization," J. Am. Chem. Soc., vol. 67, no. 3, pp. 441-447, 1945.

10.J. SIMITZIS, A. STAMBOULIS, D. TSOROS, N. MARTAKIS, "Kinetics of Curing of Unsaturated Polyesters in the Presence of Organic and Inorganic Fillers," Polym. Int., vol. 43, no. 4, pp. 380-384, 1997. 
11.Y. -S YANG L. SUSPENE, "Curing of unsaturated polyester resins: Viscosity studies and simulations in pre-gel state," Polym. Eng. Sci., vol. 31, no. 5, pp. 321-332, 1991.

12.H. KUBOTA, "Curing of highly reactive polyester resin under pressure: Kinetic studies by differential scanning calorimetry," J. Appl. Polym. Sci., vol. 19, no. 8, pp. 2279-2297, 1975.

13.J. C. LUCAS, J. BORRAJO, R. J. J. WILLIAMS, “Cure of unsaturated polyester resins: 2. Influence of low-profile additives and fillers on the polymerization reaction, mechanical properties and surface rugosities," Polymer (Guildf)., vol. 34, no. 9, pp. 1886-1890, 1993.

14.S. H. MCGEE, "Curing characteristics of particulate-filled thermosets," Polym. Eng. Sci., vol. 22, no. 8, pp. 484-491, 1982.

15.X. RAMIS, "Effect of the Initiator Content and Temperature on the Curing of an Unsaturated Polyester Resin,” Polym. Sci. Phys., vol. 37, no. 18, pp. 751-768, 1999.

16.W. D. COOK, G. P. SIMON, P. J. BURCHILL, M. LAU, T. J. Fitch, "Curing kinetics and thermal properties of vinyl ester resins," J. Appl. Polym. Sci., vol. 64, no. 4, pp. 769-781, 1997.

17.M. VAFAYAN, M. H. BEHESHTY, AND H. NASIRI, "A kinetic model for the low temperature curing of an unsaturated polyester resin with single and dual initiators," Polym. Polym. Compos., vol. 15, no. 3, pp. 183-190, 2007.

18.E. L. RODRIGUEZ, "The effect of free radical initiators and fillers on the cure of unsaturated polyester resins," Polym. Eng. Sci., vol. 31, no. 14, pp. 1022-1028, 1991.

19.J. L. VILAS, J. M. LAZA, M. T. GARAY, M. RODRIGUEZ, L. M. LEON, "Unsaturated polyester resins cure: kinetic, rheologic, and mechanical dynamical analysis. II. The glass transition in the mechanical dynamical spectrum of polyester networks," J. Polym. Sci. Part B Polym. Phys., vol. 39, no. 1, pp. 146-152, 2001.

20.L. LI, X. CAO, L. J. LEE, "Effect of dual-initiator on low temperature curing of unsaturated polyester resins," Polymer (Guildf)., vol. 45, no. 19, pp. 6601-6612, 2004.

21.X. CAO AND L. J. LEE, "Control of volume shrinkage and residual styrene of unsaturated polyester resins cured at low temperatures. II. Effect of comonomer," Polymer (Guildf)., vol. 44, no. 5, pp. 15071516, 2003.

22.J. L. MARTIN, "Kinetic analysis of an asymmetrical DSC peak in the curing of an unsaturated polyester resin catalysed with MEKP and cobalt octoate," Polymer (Guildf)., vol. 40, no. 12, pp. 34513462, 1999.

23.C. ANDRONESCU, P. O. STÃNESCU, S. A. GAREA, H. IOVU, "Influence of curing protocol of benzoxazine monomer based on aromatic diamines against the degradation behaviour of the resulted polybenzoxazines," Mater. Plast., 50(2), 2013, 146-151

24.X. RAMIS J. M. SALLA, "Effect of the inhibitor on the curing of an unsaturated polyester resin," Polymer (Guildf)., vol. 36, no. 18, pp. 3511-3521, 1995.

25.Y. J. HUANG J. S. LEU, "Curing of unsaturated polyester resins. Effects of temperature and initiator: 1. Low temperature reactions," Polymer (Guildf)., vol. 34, no. 2, pp. 295-304, 1993.

26.A. J. ROJAS, J. BORRAJO, R. J. J. WILLIAMS, "The curing of unsaturated polyester resins in adiabatic reactors and heated molds," Polym. Eng. Sci., vol. 21, no. 17, pp. 1122-1127, 1981.

27.J. AMPUDIA, E. LARRAURI, E. M. GIL, M. RODRIGUEZ, L. M. LEON, "Thermal scanning rheometric analysis of curing kinetic of an epoxy resin. I. An anhydride as curing agent," J. Appl. Polym. Sci., vol. 71, no. 8, pp. 1239-1245, 2002.

28.S. Y. KIM, D. G. CHOI, S. M. YANG, "Rheological Analysis of the Gelation Behavior of Tetraethylorthosilane/Vinyltriethoxysilane Hybrid Solutions," Korean J. Chem. Eng., vol. 19, no. 1, pp. 190-196, 2002.

29.C. N. CASCAVAL A. MIJA, "Liquid crystalline epoxy thermosets," Mater. Plast., 45(4), 2008, 339344 
30.F.MUSTATA,"Synthesis and characterization of novel methylenedianiline/tertbutylphenol formaldehyde resins as hardeners for epoxy resins," Mater. Plast., 47(2), 2010, 146-152

31.P. J. FLORY, Principles of Polymer Chemistry (The George Fisher Baker Non-Resident Lectureship in Chemistry at Cornell University). 1953.

32.P. BEAUNEZ, G. HELARY, G. SAUVET, "Role of N,N-dimethyl-para-toluidine and Saccharin in the Radical Polymerization," J. Polym. Sci. Part A Polym. Chem., vol. 32, no. 8, pp. 1471-1480, 1994. 33.G. L. BATCH C. W. MACOSKO, "Kinetic model for crosslinking free radical polymerization including diffusion limitations," J. Appl. Polym. Sci., vol. 44, no. 10, pp. 1711-1729, 1992.

34.M. HARSCH, J. KARGER-KOCSIS, M. HOLST, "Influence of fillers and additives on the cure kinetics of an epoxy/anhydride resin," Eur. Polym. J., vol. 43, no. 4, pp. 1168-1178, 2007.

Manuscript received: 20.11 .2019 